\title{
Chiasmal damage shown by optical coherence tomography: case illustration
}

\author{
Pamela R. Sherwood, MD, ${ }^{1}$ Thomas R. Hedges III, MD, ${ }^{1}$ \\ Carlos E. Mendoza-Santiesteban, MD, ${ }^{1,3}$ Carl B. Heilman, MD, ${ }^{2}$ and Julian K. Wu, MD² \\ ${ }^{1}$ New England Eye Center at Tufts Medical Center; ${ }^{2}$ Department of Neurosurgery at Tufts Medical Center, School of \\ Medicine, Tufts University, Boston, Massachusetts; and ${ }^{3}$ Bascom Palmer Eye Institute, University of Miami, Miller \\ School of Medicine, Miami, Florida
}

https://thejns.org/doi/abs/10.3171/2018.1.JNS171915

KEYWORDS optical coherence tomography; ganglion cell complex; visual fields; chiasm; diagnostic technique

\begin{abstract}
A 65-YEAR-OLD man slipped and hit his head. A head CT scan showed a pituitary mass. Visual acuities were normal, and visual fields showed bitemporal paracentral depression (Fig. 1A). Magnetic resonance imaging showed a large sellar/suprasellar mass compressing the optic chiasm (Fig. 1B). Optical coherence tomographic ganglion cell complex (GCC) layer analysis showed binasal thinning in both eyes (Fig. 1C).

Patients with large pituitary adenomas are typically referred for visual field testing to evaluate the effects of optic chiasmal compression. However, visual perimetry testing is subjective and sometimes difficult to interpret. ${ }^{2}$ A new algorithm can segment and quantify the GCC layer of the retina on optical coherence tomography (OCT), which uses light waves to visualize a portion of the retina with an image resolution of $5 \mu \mathrm{m}$ axially. Imaging is typically done by a technician, does not require pupil dilation, and takes only several minutes to perform. Eye movements and cataracts can reduce the quality of the image.

Areas of thinning on OCT GCC analysis have been shown to correlate with areas of visual field loss from optic chiasmal compression, ${ }^{3,4}$ and GCC loss may be present in patients without visual field defects either pre- or post-
\end{abstract}

operatively. ${ }^{1}$ We previously showed that patients with less thinning on OCT GCC analysis before surgical decompression had better postoperative outcomes, suggesting that GCC measurements may offer improved prognostic capability as compared to that with perimetry alone. ${ }^{5}$

\section{References}

1. Cennamo G, Auriemma RS, Cardone D, Grasso LFS, Velotti N, Simeoli C, et al: Evaluation of the retinal nerve fibre layer and ganglion cell complex thickness in pituitary macroadenomas without optic chiasmal compression. Eye (Lond) 29:797-802, 2015

2. Fujimoto N, Saeki N, Miyauchi O, AdachiUsami E: Criteria for early detection of temporal hemianopia in asymptomatic pituitary tumor. Eye (Lond) 16:731-738, 2002

3. Jeong AR, Kim EY, Kim NR: Preferential ganglion cell loss in the nasal hemiretina in patients with pituitary tumor. J Neuroophthalmol 36:152-155, 2016

4. Moon CH, Hwang SC, Ohn YH, Park TK: The time course of visual field recovery and changes of retinal ganglion cells after optic chiasmal decompression. Invest Ophthalmol Vis Sci 52:7966-7973, 2011

5. Tieger MG, Hedges TR III, Ho J, Erlich-Malona NK, Vuong LN, Athappilly GK, et al: Ganglion cell complex loss in chiasmal compression by brain tumors. J Neuroophthalmol 37:7-12, 2017 
A

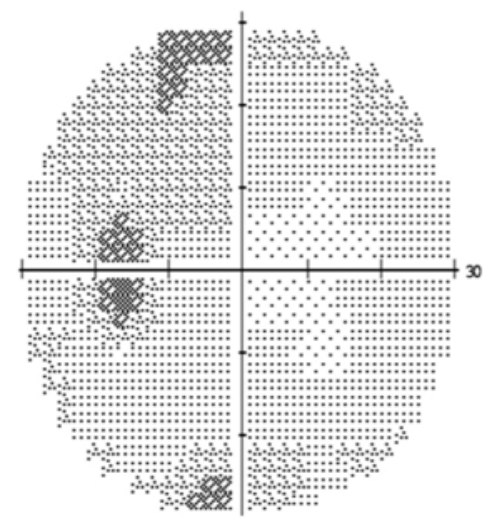

Left Eye

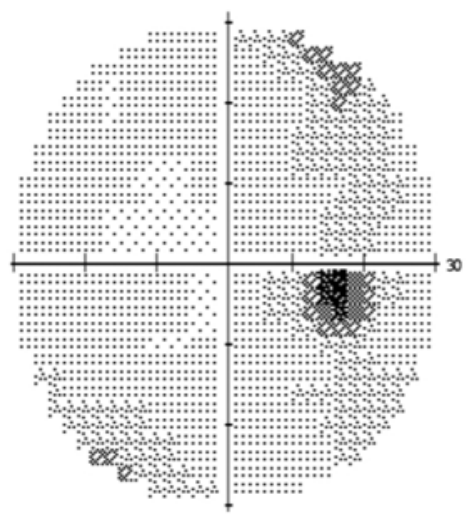

Right Eye
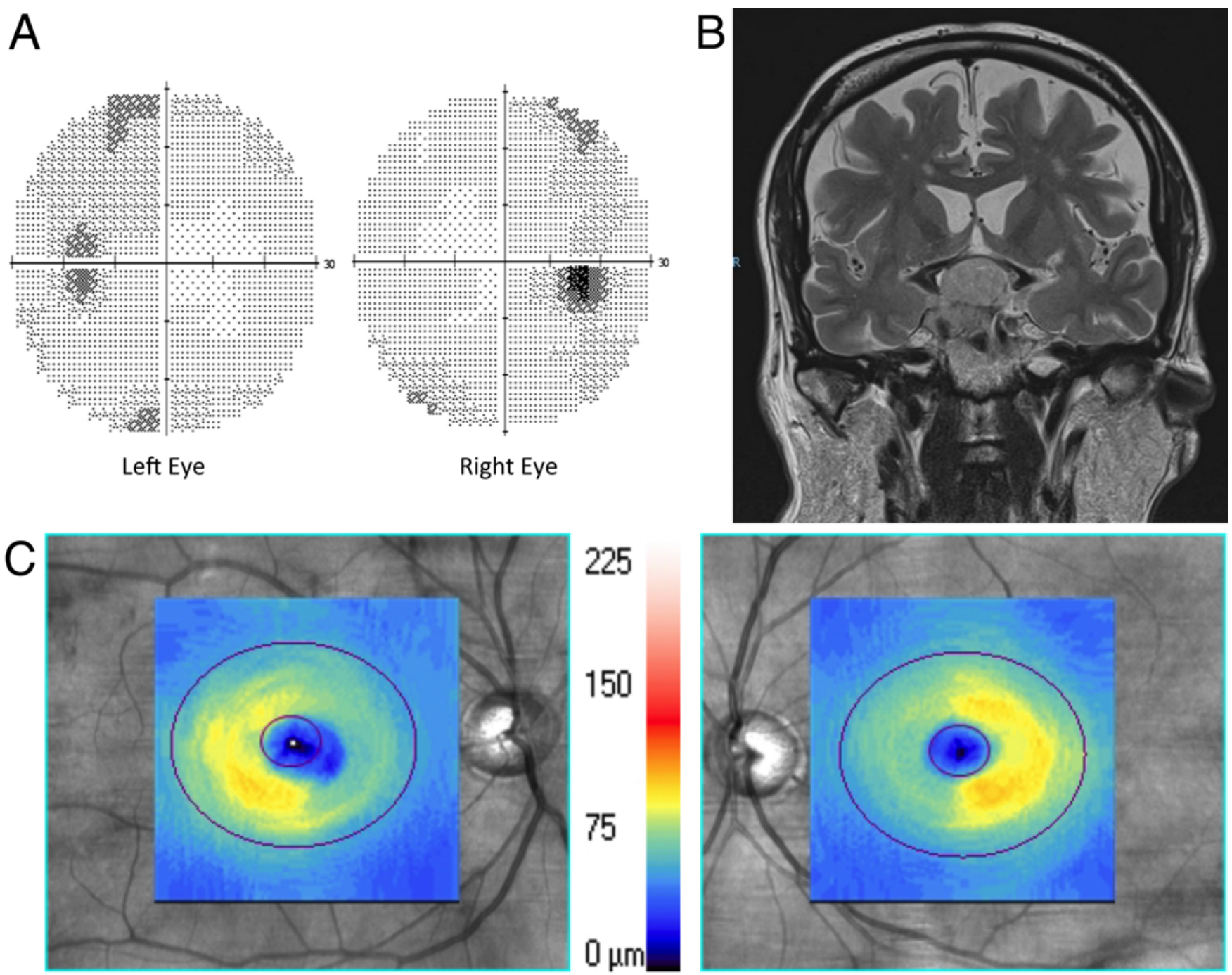

FIG. 1. A: Visual field analysis shows mild bitemporal paracentral depression in both eyes. B: Coronal T2-weighted MR image shows a large sellar mass extending superiorly and compressing the optic chiasm. C: The thickness map of the GCC overlays an infrared fundus image. Thickness is compared to a normative database. Shades of color correspond to thickness measurements in micrometers (middle legend). Yellow indicates normal-range thickness of the GCC layer. More blue/green areas on the GCC analysis signify thinning. The deeper blue the color, the more significantly the thinning deviates from normal on this particular map. Thus, in this patient, GCC analysis shows significant binasal thinning in both eyes, demonstrated topographically as the blue/green areas on the thickness maps.

\section{Disclosures}

This research was supported in part by The Massachusetts Lions Clubs/Research to Prevent Blindness Challenge Grant, the Dysautonomia Foundation Inc., and Carl Zeiss Meditec Inc.

\section{Author Contributions}

Conception and design: Hedges, Sherwood, Mendoza-
Santiesteban. Acquisition of data: Hedges, Sherwood. Analysis and interpretation of data: Hedges, Sherwood. Drafting the article: Hedges, Sherwood. Critically revising the article: Sherwood, Heilman, Wu. Reviewed submitted version of manuscript: Sherwood, Heilman, Wu. Approved the final version of the manuscript on behalf of all authors: Hedges. Administrative/technical/material support: Sherwood. Study supervision: Hedges, Heilman, Wu. 